\title{
RESENHAS
}

SOARES, Gláucio Ary \& RENNÓ, Lúcio. (orgs.). 2006. Reforma política : lições da história recente. Rio de Janeiro : Fundação Getúlio Vargas.

\section{QUÃO DEMOCRÁTICA É A "CONSTITUIÇÃO" BRASILEIRA?}

\author{
Sérgio Soares Braga \\ "Sempre que falarmos de liberdade e de direitos, não devemos \\ nunca nos esquecer de perguntar: liberdades ou direitos para quem?”
}

(Robert Dahl).

O título desta resenha alude a um importante livro - infelizmente ainda não traduzido para o português escrito pelo cientista político Robert Dahl, em que o venerando politólogo norte-americano defende a necessidade de mudanças substanciais (o que por aqui denominamos de "reforma política") nas regras constitucionais e legais que regulam o funcionamento da democracia parlamentar norte-americana ${ }^{1}$. Para o autor, apesar de ter dado origem a uma poliarquia "governável" e razoavelmente estabilizada ao longo do tempo, existem uma série de elementos antidemocráticos presentes na tradição constitucional norte-americana que podem e devem ser corrigidos e modificados, caso avalie-se o desempenho desse sistema político pelos parâmetros normativos que devem orientar os analistas políticos e cidadãos comprometidos com os valores e os princípios da igualdade política democrática. Na visão de Dahl, tais princípios consistem em assegurar o exercício dos direitos humanos fundamentais à maior parcela da população, a máxima ampliação da cidadania política aos habitantes do território de um país, assim como o direito desses cidadãos a terem expressas e representadas, da maneira mais transparente e eficaz possível, suas vontades na arena política².

Dentre os elementos antidemocráticos vigentes no sistema político norte-americano e que o afastam da concretização integral dos princípios democráticos, Dahl aponta como os mais relevantes os seguintes: 1) o sufrágio majoritário uninominal que sub-representa as minorias e cria “maiorias artificiais", gerando um sistema partidário artificialmente controlado por dois grande partidos cada vez mais homogêneos, o que contribui para o aumento da apatia eleitoral e para a despolitização dos cidadãos norte-americanos; 2) um Senado Federal situado entre os mais antidemocráticos e desproporcionais do mundo ${ }^{3}$, com grande presença de políticos oriundos de estados mais atrasados do ponto de vista socioeconômico e político, o que termina concedendolhes um poder de veto sobre as decisões tomadas pela câmara baixa, inteiramente desproporcional à sua efetiva relevância numérica e socioeconômica na sociedade norte-americana; 3) um Colégio Eleitoral que consiste antes de mais nada em uma forma de legitimação da eleição do Presidente da República por delegados vinculados às oligarquias partidárias estaduais, subtraindo à massa dos eleitores o direito ao escrutínio direto do principal mandatário do país e 4) um corpo judiciário não-eletivo (a Suprema Corte) com excessivo poder revisional e de veto em relação às normas emanadas do Congresso norte-americano, prejudicando assim a concretização do ideal da soberania popular e colocando um novo filtro à livre expressão da vontade popular dos cidadãos estadunidenses por meio dos corpos eletivos.

\footnotetext{
1 Publicado originalmente nos EUA em 2001 com o título de How Democratic is the American Constitution? (Yale University, 2001), a obra teve tradução espanhola publicada pela Fondo de Cultura Económica (DAHL, 2003).

2 De acordo com Dahl (2003, p. 147), “Se acreditamos que todos os seres humanos nascem iguais, que estão dotados de certos direitos inalienáveis, que entre estes estão os direitos à vida, à liberdade e à busca da felicidade; que é para assegurar esses direitos que se instituem os governos do povo, derivando seus poderes da autorização e do consentimento dos governados, então nos vemos obrigados a defender a meta da igualdade política”.

3 Segundo o autor, “o grau de representação desigual no Senado dos Estados Unidos somente é superado por aqueles observados nos senados do Brasil e da Argentina” (DAHL, 2003, p. 59).
} 
Para equacionar essas anomalias, Robert Dahl sugere uma "reforma política” que elimine os vários aspectos antidemocráticos presentes nas instituições políticas dos EUA, aproximando seu sistema político daquelas democracias parlamentares que foram qualificadas por Arendt Lijphart, em seu livro clássico sobre os "modelos de democracia” (LIJPHART, 2003), de “democracias consensuais”, predominantes nos países da Europa continental. Dentre essas medidas de reforma, destacam-se a adoção do sufrágio proporcional; a redução das prerrogativas decisórias do Senado, restringindo-as apenas àqueles assuntos que estejam relacionados mais de perto à manutenção da federação e do pacto federativo, evitando assim que essa câmara transforme-se em uma instância de veto às decisões emanadas da Câmara dos Deputados; a eleição direta do próprio chefe do poder Executivo pelos sufrágios populares, extinguindo ou tornando mais democrática a eleição do Colégio Eleitoral que nomeia o Presidente da República; a redução das prerrogativas de veto da Suprema Corte sobre as leis aprovadas pela Câmara de Representantes, eleita pelo povo, dentre outras medidas destinadas a tornar mais democrática a democracia norte-americana ${ }^{4}$.

É bom que se esclareça que o livro de Dahl foi escrito e publicado sob o impacto da fraude nas eleições presidenciais norte-americanas de dezembro de 2000, que elegeram G. Walker Bush Presidente da República, e pouco antes dos atentados de 11 de setembro e da legislação de exceção que se lhe seguiu a pretexto do combate ao "terrorismo", o que talvez tenha contribuído - direta ou indiretamente - para o esvaziamento do debate sobre a natureza mais ou menos democrática das instituições políticas estadunidenses, que Robert Dahl provavelmente pretendia estimular com seu sugestivo opúsculo.

Tudo isso para dizer que acreditamos ser altamente recomendável que o leitor interessado nos debates sobre a chamada "reforma política" aqui no Brasil procure consultar o livro de Dahl - nem que seja para recuperar um pouco sua auto-estima, tão abalada com os freqüentes escândalos do noticiário político. Pois, a partir da leitura do livro, pode-se perceber que a existência de um certo descontentamento difuso com a forma de funcionamento das democracias parlamentares realmente existentes nos sistemas sociais capitalistas contemporâneos não é monopólio dos democratas e dos cidadãos brasileiros, nem mesmo da democracia e dos cidadãos dos países da periferia do sistema capitalista de uma maneira geral. Muito pelo contrário: também nos países economicamente avançados e de democracia parlamentar mais institucionalizada é comum e cada vez mais freqüente o debate sobre a reforma de algumas das regras fundamentais que organizam os respectivos sistemas políticos. Como se sabe, chegou-se mesmo a cunhar, nos países de democracia parlamentar mais institucionalizada e estável, uma expressão - critical citizens, título de um conhecido livro da cientista política Pippa Norris (1999) - para designar a atitude e o sentimento generalizados de parcela significativa dos cidadãos modernos que, apesar de aderirem genericamente a valores e a princípios democráticos tais como os do reconhecimento do pluralismo, da igualdade e da tolerância políticas e da necessidade de criação de mecanismos de fiscalização e de controle permanentes sobre aqueles que exercem o poder, mostram-se insatisfeitos com as formas de corporificação desses valores nas instituições das modernas democracias parlamentares realmente existentes, ditas "representativas".

Não é de surpreender, portanto, que a demanda por mudança nas regras eleitorais e partidárias seja recorrente em vários países de democracia mais institucionalizada e não apenas no Brasil. Por outro lado, também no tocante ao campo político mais conservador podemos detectar uma pressão pela inclusão na agenda pública de medidas destinadas à realização de uma "reforma política" (e. g., SERRA, 1995; JAGUARIBE, 1999). Dessa perspectiva, entretanto, a questão é posta a partir de parâmetros normativos simetricamente opostos aos explicitados por Dahl e pelos critical citizens e concentram-se em medidas destinadas ao aumento da capaci-

\footnotetext{
4 É bom sublinhar que o próprio Dahl admite ser cético em relação à exeqüibilidade da implantação dessas propostas, ao menos no curto prazo, o que não o desobriga de apresentá-las de maneira sistemática à opinião pública, nem que seja para desmistificar a falácia amplamente difundida por analistas políticos conservadores, de tomar as democracias majoritárias anglo-saxãs como os únicos modelos bem-sucedidos de democracia parlamentar na história recente. Apenas para citar um exemplo desse poder antidemocrático de veto do Senado norte-americano, segundo Dahl (2003, p. 99): “Foram apresentadas mais de 700 propostas na Câmara dos Representantes para modificar ou abolir o sistema eleitoral (Colégio Eleitoral e distrito uninominais). Nenhuma delas foi adiante. Como é previsível, a vala comum das emendas constitucionais destinadas a alterar o Colégio Eleitoral é o Senado, que, como já vimos, é a cidadela da representação desigual”. Dahl menciona ainda uma emenda constitucional instituindo a eleição direta para Presidente da República nos EUA que foi aprovada em 1989 pela House of Representatives com $89 \%$ dos votos dos deputados norte-americanos e que foi em seguida rejeitada no Senado por uma minoria de parlamentares originários dos estados menos populosos.
} 
dade dos diferentes sistemas políticos de produzir ou não a almejada "governabilidade”, via de regra definida em termos excessivamente abstratos.

Essas longas considerações introdutórias são necessárias para melhor contextualizar a relevância do livro para o qual gostaríamos de chamar a atenção do leitor desta resenha. Pois, para que não nos percamos na profusão de palpites, opiniões, sugestões de regras, recomendações e posições políticas que constituem o "varejão" de propostas em que se transformou o debate sobre a reforma política no Brasil, é necessário que façamos desde logo um esforço para definir os parâmetros normativos a partir dos quais podemos avaliar o "desempenho" das modernas democracias parlamentares em geral e da democracia brasileira em particular. E, se for o caso, pode-se chegar até mesmo à conclusão de que elas devam permanecer como estão, ou seja, temse o direito de recusar quaisquer propostas de alteração ou de "reforma" das regras que regulamentam o sistema de representação de tais democracias.

Nesse sentido, o livro organizado por Soares e Rennó destaca-se de outros trabalhos já publicados sobre a temática da reforma política no Brasil ${ }^{5}$ pela preocupação em fornecer evidências empíricas mais robustas e analiticamente estruturadas sobre os temas em debate, que permitam uma discussão mais fundamentada sobre alguns dos principais pontos que constituem a agenda da "reforma política" no Brasil, afastando-se assim do "achismo" e da "palpitologia" algo esquizofrênica em que se transformaram tais controvérsias, inclusivamente em alguns meios acadêmicos, em que a ansiedade de posicionar-se sobre os pontos que fazem parte da agenda de reformas é inversamente proporcional ao trabalho de fundamentação empírica e analítica dos posicionamentos exarados.

Como é explicado pelos autores no "Prefácio" (SOARES \& RENNÓ, 2006), o livro constitui-se de um conjunto de comunicações apresentadas em um seminário realizado pela Câmara dos Deputados em julho de 2003, com o objetivo de debater a questão da reforma política e o funcionamento das instituições políticas brasileiras e reúne importantes trabalhos de alguns dos principais analistas políticos que produziram pesquisas relevantes sobre a temática. Também como é esclarecido pelos autores, o livro divide-se em quatro partes, cada uma delas dedicada a discutir uma dimensão importante das propostas em tramitação na Câmara dos Deputados que podem ser incluídas sob a rubrica de "reforma política”6. Essas dimensões ou grandes áreas temáticas são as seguintes: 1) sistemas eleitorais, decisão de voto e transparência; 2) representação dos grupos de interesse nas arenas eleitoral e parlamentar; 3) partidos políticos e sistema partidário e 4) relações entre os poderes Executivo e Legislativo.

A primeira parte do livro, "Sistema eleitoral e accountability", é constituída por textos dedicados a analisar diversas dimensões da relação estabelecida entre eleitor e seu "representante” na arena eleitoral. Assim, Jairo Nicolau (2006a, p. 23-33), apresenta os resultados de uma pesquisa do Instituto Universitário de Pesquisas do Rio de Janeiro (Iuperj) que confirmam a percepção generalizada sobre o excessivo grau de personalização das eleições brasileiras e a organização dos pleitos eleitorais em fracas bases partidárias: "Os dados da Pesquisa Iuperj-2002 deixam claro que, nas eleições para a Câmara dos Deputados, os partidos contam pouco e a escolha eleitoral ocorre, sobretudo, em bases personalizadas” (idem, p. 30). Entretanto, a partir da constatação de tal

\footnotetext{
5 A referência básica para qualquer debate mais sistemático sobre reforma política no Brasil é o Relatório sobre a reforma político-partidária, resumindo os trabalhos da comissão de que foi Relator o Senador Sérgio Machado (então no Partido da Social-Democracia Brasileira (PSDB) do Ceará) que funcionou no Senado Federal durante o primeiro governo Fernando Henrique Cardoso (MACHADO, 1998). Grosso modo, esse relatório sistematiza as propostas de mudança do sistema político brasileiro do campo político conservador então no poder (a coalizão PSDB-Partido da Frente Liberal (PFL)), tais como a adoção do voto distrital misto, aumento de cláusula de barreira para 5\%, adoção do sufrágio facultativo, restrições à propaganda eleitoral, dentre outras propostas. Esse relatório foi examinado criticamente, sendo inclusivamente taxado de "neoliberal”, em trabalhos tais como os de Tavares (1998) e Dirceu e Ianoni (1999). Dentre os trabalhos mais recentes que abordam de maneira mais sistemática a questão da reforma política, podemos mencionar os de Benevides, Vanuchi e Kerche (2003), Moraes e Hermanns (2003) e Anastasia e Avritzer (2006), que também examinam uma grande quantidade de temas relacionados à reforma política no Brasil. A nosso ver, nenhum deles, entretanto, contém trabalhos de densidade analítica e fundamentação empíricas análogos àqueles incluídos na coletânea organizada por Soares e Rennó.

6 A reconstituição efetuada pelos organizadores do livro das principais proposições referentes à reforma política que tramitaram no Congresso Nacional nas últimas legislaturas é um tanto quanto precária e assistemática (SOARES \& RENNÓ, 2006, p. 11-16). Para informações mais completas a respeito das propostas relativas a essa área temática é recomendável a consulta aos trabalhos de Rabat (2003), Amorim e Cintra (2003) e Braga e Belache (2004).
} 
fenômeno, limita-se a enumerar os trade-offs existentes entre os vários sistemas de lista vigentes nas democracias capitalistas contemporâneas, sem se posicionar com clareza em relação à maior ou à menor pertinência da adoção de nenhum deles, coisa que o fará em artigo mais recente em que defende o sistema de listas flexível (NICOLAU, 2006b).

Quase o mesmo pode ser dito do artigo de Alberto Almeida (2006, p. 34-46) a respeito da “amnésia eleitoral” do eleitor brasileiro. Após resumir dados comparados de surveys sobre a lembrança do voto para vários cargos eletivos em diferentes países, demonstra que o Brasil, juntamente a outros países como Portugal e Polônia, é o país que apresenta maior grau de "amnésia eleitoral” entre todas as democracias analisadas. Também aqui fica inconclusivo qual o melhor remédio institucional para tratar de tal "amnésia”: o autor sugere indistintamente o sistema proporcional de lista fechada e o sistema majoritário para reduzi-la, partindo da premissa, bastante equivocada, de que "Qualquer mudança que seja feita para diminuir o número de candidatos ou obrigar, em maior ou menor medida, o voto em partidos irá ser [sic] uma mudança para melhor” (idem, p. 46), sem atentar para as significativas diferenças sistêmicas produzidas no plano macro-político pela adoção de um ou outro sistema eleitoral (LIJPHART, 2003).

O terceiro texto é de autoria de um dos organizadores da coletânea, Lúcio Rennó (2006, p. 47-68), abordando o tema dos determinantes da decisão de voto em contextos eleitorais complexos (i.e., com grande número de candidatos por circunscrição), como o brasileiro. A partir de estudos do desempenho do Índice de Informação sobre Deputados Federais (IIDF) em dois municípios brasileiros (Juiz de Fora e Caxias do Sul), chega à conclusão de que "o número de candidatos, como componente central da complexidade eleitoral, afeta negativamente o nível de conhecimento do eleitor”. Apesar disso, conclui, em contraposição aos autores anteriormente citados, que não são necessárias alterações substanciais no sistema eleitoral brasileiro para equacionar tais disfuncionalidades (idem, p. 62-63).

A segunda parte do livro, "Vieses na representação de grupos sociais e econômicos", é composta por quatro instigantes artigos em que se examinam vários aspectos da representação dos grupos sociais nas arenas eleitoral e parlamentar. Assim, Mercedez Mateo-Diaz (2006, p. 70-110), em um informativo artigo retomando resultados de pesquisas anteriores, faz um meticuloso estudo comparativo dos diferentes modelos de sistemas de cotas e políticas afirmativas em diversos países de democracia parlamentar mais institucionalizada, detendo-se no exame do caso belga. Mateo-Diaz chega à conclusão de que as políticas afirmativas de cotas promovem efetivamente efeitos substanciais no sentido de aumentar a presença da mulher na política e de incluir as minorias de uma forma geral, posicionando-se com clareza não apenas a favor da manutenção do sistema de cotas, mas de sua maior institucionalização e da adoção de princípios complementares para sua efetiva consolidação (idem, p. 108). Segue-se um informativo e denso estudo de Clara Araújo (2006, p. 111-132), um dos mais instigantes artigos da coletânea, em que é efetuado um balanço dos resultados da adoção do sistema de quotas no Brasil. A autora demonstra que, nos sistemas eleitorais proporcionais (ou "consocionais", para usar a expressão de Lijphart), a participação feminina na arena parlamentar é significativamente superior à observada nos países de democracia majoritária, chegando ainda à conclusão de que "O tipo de sistema de representação tem papel determinante [na presença das mulheres na arena parlamentar]: as cotas tendem a ser mais facilmente implementadas em sistemas de representação proporcional, já que é mais viável adota-lás" (idem, p. 128). Por esse motivo, a autora manifesta-se firmemente a favor da manutenção de tal sistema no Brasil, repudiando a adoção de qualquer variante de sistema majoritário, seja ele puro, seja ele “misto”, diferenciando-se claramente assim de uma certa ambigüidade em relação aos sistemas eleitorais constatada em textos anteriores.

O último tópico abordado nesse segundo bloco do livro refere-se a um dos pontos mais polêmicos constantes das várias propostas de "reforma política" em tramitação no Congresso Nacional: a questão do financiamento das campanhas eleitorais, examinada por David Samuels em informativo artigo (SAMUELS, 2006, p. 133-153). A partir da análise meticulosa dos dados das prestações de contas dos candidatos disponíveis no portal eletrônico do Tribunal Superior Eleitoral (TSE), o autor chega à conclusão de que, de fato, com base nas evidências disponíveis, é correta a percepção corrente de que o Brasil é um país cujos custos de campanha são excessivamente elevados. Não só são elevados como a maior parte do financiamento vem de empresas que se beneficiam de informações e de investimentos públicos, tais como bancos e empreiteiras, o que tende a gerar uma relação promíscua entre políticos e grandes empresas, que se expressa por exemplo na ineficiência alocativa de algumas das emendas sugeridas aos orçamentos públicos pelos parlamentares. Apesar de detectar várias distorções no sistema de financiamento de campanhas existente no Brasil, Samuels no entanto opõe-se 
vementemente a qualquer proposta de adoção de financiamento público exclusivo, optando pela adoção de um sistema privado mais regulamentado, por meio de medidas como a redução da quantia máxima de doação de campanha de pessoas físicas e jurídicas, com uma fiscalização eficiente pelos tribunais eleitorais e pela opinião pública das fontes de financiamento dos candidatos, inclusivamente com acesso público a essas contas na internete, como ocorre nos EUA.

Da terceira parte do livro, "Sistema partidário", constam artigos de outros pesquisadores que buscam examinar as tendências de funcionamento do sistema partidário brasileiro, também retomando e aprofundando resultados substantivos de pesquisas empiricamente orientadas efetuadas anteriormente, assim como ocorre com os demais trabalhos contidos na coletânea. Carlos Ranunfo Melo (2006, p. 157-175), demonstra que o sistema partidário brasileiro caminhou nos últimos anos em direção a uma relativa estabilização e a uma institucionalização de um pluripartidarismo de feição moderada com algo em torno de sete partidos relevantes, com presença e força política maiores na arena parlamentar daquelas agremiações que lançam sistematicamente candidatos às eleições majoritárias, especialmente presidenciais. Demonstra, entretanto, que ainda existem fortes obstáculos para uma institucionalização maior do sistema partidário brasileiro, tais como o excesso de migrações partidárias, a ausência de listas partidárias (mesmo que "flexíveis"), a ausência de proporcionalidade na distribuição de cadeiras a partir no quociente partidário e a forma de financiamento das campanhas eleitorais, sugerindo ainda uma série de medidas para corrigir tais deficiências.

André Marenco dos Santos (2006, p. 176-192) aborda o tema da fidelidade partidária, decompondo-a em suas dimensões mais relevantes, tais como a estabilidade dos resultados eleitorais, a disciplina das decisões legislativas e a continuidade das carreiras políticas, todos esses elementos inter-relacionados ao processo mais amplo de institucionalização dos partidos políticos brasileiros. Afirma que todo "o problema consiste em que esses três vetores não convergem, de forma simultânea e necessária, em direção e sentido" e que, embora haja evidências consistentes do comportamento coeso e disciplinado dos partidos na arena parlamentar e de diminuição da volatilidade do voto do eleitorado brasileiro, permanece como "problema” não solucionado do sistema partidário a taxa alta de migrações partidárias que, "além de representar uma violação na correspondência entre votos e cadeiras legislativas, acentua problemas de coordenação e incrementa os custos para lealdades partidárias, ao promover uma via alternativa ao recrutamento partidário endógeno, como acesso à carreira política" (idem, p. 179). O autor recorre ao conceito de "racionalidade contextual" para explicar os diferentes padrões migratórios vigentes nas várias regiões e unidades administrativas brasileiras, concluindo a partir daí que a variável que se correlaciona mais fortemente com as taxas de migração partidária é o tempo de filiação prévia do parlamentar ao partido. Sendo assim, o autor sugere como forma de inibir as migrações partidárias a extensão do prazo mínimo de filiação para candidaturas a cargos eletivos, opondo-se no entanto à alterações mais bruscas no sistema partidário e eleitoral brasileiro, como a adoção de listas pré-ordenadas ou a fórmula majoritária mista como soluções para as distorções observadas.

Segue-se o artigo de Simone Bohn (2006, p. 192-227) revisitando o velho tema da distorção regional e dos estados na representação do Congresso Nacional, que já foi objeto de estudos pioneiros inclusivamente por um dos organizadores da coletânea (SOARES, 2001). A autora mostra que, assim como ocorre em países federativos bicamerais como os EUA, no Brasil há uma forte distorção regional na distribuição dos votos nos órgãos parlamentares, que afeta significativamente as votações em plenário, dificultando ainda mais a vitória das propostas de partidos de centro-esquerda ou mesmo de segmentos do campo político conservador situados em estados economicamente mais desenvolvidos. Particularmente interessante é a ilustração da tese de que o caráter federativo do Estado brasileiro determina a existência de uma heterogeneidade de culturas políticas no seio dos próprios partidos políticos, formando-se coalizões de veto que impedem a aprovação de várias medidas contrárias aos interesses das oligarquias dos estados mais atrasados e dando origem a um complexo padrão de alianças dos partidos por ocasião das votações em plenário. A autora conclui afirmando taxativamente que "A redefinição do número de cadeiras dos estados na Câmara dos Deputados, com base no tamanho de suas populações, é uma etapa inadiável na direção do aperfeiçoamento da qualidade do regime democrático brasileiro" (BOHN, 2006, p. 221; grifo no original), embora não detalhe nenhuma proposta concreta para tal redefinição.

Maria do Socorro Braga (2006, p. 228-245) aborda o intricado tema das coligações partidárias no Brasil, especialmente o das relações entre coligações e proporcionalidade da representação. A autora chega à conclusão de que a legislação sobre coligações eleitorais no Brasil afeta a distribuição de cadeiras, favorecendo os pequenos partidos, embora não altere significativamente a fragmentação partidária e a distribuição de poder no 
Congresso Nacional entre as cinco forças partidárias principais. Para corrigir algumas das distorções observadas, sugere medidas tais como a proibição de coligações cum eliminação conjunta da forma de cálculo atual do quociente eleitoral, propondo a adoção do método de D’Hondt para o cálculo de cadeiras nas eleições proporcionais, sem dúvida uma forma de cálculo que espelharia mais fielmente a vontade do eleitor, especialmente em estados mais atrasados.

A quarta e última parte da coletânea, "Relação Executivo-Legislativo”, é formada por estudos de importantes pesquisadores que contribuíram para o aumento de nosso conhecimento das relações entre os poderes Executivo e Legislativo no sistema político brasileiro, bem como da relação entre processo de governo e dinâmica partidário-parlamentar nos vários subperíodos de funcionamento da democracia brasileira.

Inicialmente, Figueiredo e Limongi (2006, p. 249-280), aprofundando os resultados de trabalhos de grande influência na Ciência Política brasileira recente (FIGUEIREDO \& LIMONGI, 1999), contrastam o desempenho do sistema político nas duas etapas da democracia presidencialista partidária na história republicana brasileira (1946-1964 e a partir de 1988). Confirmando resultados de estudos anteriores (SANTOS, 2003), os autores fornecem uma série de evidências mostrando que vigoraram padrões diferentes de relações entre os poderes Executivo e Legislativo nessas duas experiências democráticas, com um maior peso do Executivo no processo decisório e dos partidos políticos na formação das coalizões e de construção das bases governistas no período após 1988. Devido a essas características, o atual sistema político democrático brasileiro está menos propenso a crises de governabilidade. A causa de tal padrão, reiteram os autores, é o maior poder de agenda colocado nas mãos do chefe do poder Executivo e dos líderes partidários, que dão maior capacidade de coordenação a tais atores, minimizando o risco de crises de governabilidade significativas. Uma das conclusões inferidas é a de que não há necessidade de alterações substanciais nas regras que regulam o funcionamento da democracia brasileira, caso o fim almejado por tais reformas seja a obtenção de governabilidade e a coerência das políticas governamentais (LIMONGI, 2005).

Segue-se um artigo de Fabiano Santos (2006, p. 281-295), em que o autor chega a conclusões um pouco diferentes, ao explicitar com maior clareza os parâmetros normativos pelos quais avalia o desempenho das instituições políticas democráticas brasileiras. Santos parte da premissa de que "As propostas de reforma política têm invariavelmente como foco a questão da governabilidade. Sugiro, no que se segue, caminho diverso para o entendimento do problema institucional brasileiro, a saber, que o aperfeiçoamento de nosso sistema político deve necessariamente passar por medidas que reduzam os instrumentos de governabilidade em mãos do [poder] Executivo" (idem, p. 283). A partir dessa perspectiva inovadora, que rompe com toda uma tradição de abordagem dos problemas institucionais brasileiros, Fabiano Santos estuda os vários cenários de interação estratégica entre Presidente da República e partidos políticos, enfatizando que os poderes de agenda nas mãos do Presidente e os líderes partidários não são os únicos nem os principais fatores para explicar o desempenho dos diferentes governos. É necessário inserir também os partidos políticos como atores relevantes na arena governativa e como portadores de preferências programáticas específicas, considerando ainda o conteúdo das opções estratégicas decididas pelos vários presidentes para lidar com tais atores nas esferas governamental e legislativa. $\mathrm{O}$ autor demonstra que as três últimas gestões governamentais apresentaram padrões diferentes no tocante a esse ponto, afastando-se o governo Lula mais dos partidos políticos majoritários da casa em comparação com as gestões anteriores. A idéia central do autor é que "em nosso presidencialismo de coalizão a governabilidade é função da existência de um programa bem definido de políticas defendido pelos parceiros. A existência desse programa é função, por sua vez, da distância do status quo em relação às políticas ideais dos partidos que compõe a coalizão" (idem, p. 285). Sendo assim, a configuração do quadro partidário e a estratégia do Presidente em relação aos partidos majoritários representados nas casas legislativas são variáveis importantes para o desempenho do sistema. Entretanto, para fazer frente a esses crônicos problemas de coordenação entre a agenda presidencial e as preferências programáticas dos atores partidários relevantes, o autor é contrário a modificações substanciais no sistema político e sugere algumas mudanças institucionais tópicas, tais como a perda de mandato do parlamentar que ocupar cargos ministeriais e a distribuição mais equânime de poder alocativo entre os poderes Executivo e Legislativo, sem explicar no entanto como mudanças tão reduzidas podem alterar de maneira significativa o desempenho dos padrões de interação observados.

Diagnósticos mais "pessimistas" sobre as relações entre Executivo e Legislativo do sistema político brasileiro (et pour cause, abertos a propostas mais ousadas de reforma) encontram-se nos trabalhos de Pereira e Mueller (2006, p. 281-295) e Amorim Neto (2006, p. 316-344). No primeiro desses textos, o ponto de partida são 
os efeitos negativos para o processo de governo do sistema eleitoral de lista aberta vigente no Brasil. O autor propõe uma sugestão de formalização das interações entre os poderes Executivo e Legislativo como um jogo complexo de interações com partidos fracos na arena eleitoral e partidos fortes na arena partidária, em que o Presidente tem dificuldades para montar sua base de governo em virtude das regras eleitorais vigentes no Brasil. Entretanto, o texto é inconclusivo no tocante à eventuais propostas de melhoria das legislações eleitoral e partidária para sanar as dificuldades enumeradas.

A coletânea é finalizada por um instigante artigo de Amorim Neto, um dos melhores textos de todo o livro, em que o autor efetua um estudo meticuloso dos diferentes arranjos institucionais passíveis de serem concretizados nos diferentes tipos de sistemas de governos, detendo-se naqueles que, talvez em uma definição excessivamente elástica, qualifica de "semipresidencialistas". A partir desse estudo comparativo das características do processo decisório em vários regimes "semipresidencialistas", o autor preconiza para o Brasil uma série de inovações institucionais de molde a aproximá-lo desse arranjo institucional, tais como a redução das prerrogativas presidenciais no processo decisório e a nomeação de um Primeiro-Ministro eleito pelo Congresso Nacional para a chefia do governo, fortalecendo assim as prerrogativas governativas formais dos partidos brasileiros. Ainda segundo o autor, "Essas reformas deveriam incluir, supondo a preservação do sistema proporcional, o estabelecimento de barreiras de entrada na Câmara e a proibição de coligações nos pleitos proporcionais, a fim de evitar a proliferação de microlegendas; a substituição de listas abertas pelo [sistema] de listas fechadas, para reforçar a autoridade das lideranças partidárias sobre seus deputados; e, para coibir a migração partidária, os mandatos parlamentares deveriam pertencer aos partidos e não aos legisladores” (idem, p. 339).

Em suma: como pode ser percebido pelo resumo acima, são múltiplos os temas abordados ao longo do livro e inexiste unidade teórica ou consenso prescritivo entre os vários colaboradores da coletânea, o que pode dificultar o acompanhamento da argumentação pelo leitor não iniciado em todos matizes dos debates sobre as instituições políticas brasileiras, ocorridos recentemente entre alguns dos principais estudiosos do assunto no Brasil.

Respondendo à questão colocada inicialmente no título desta resenha, verificamos que os trabalhos constantes do livro organizado por Soares e Rennó fornecem-nos preciosos subsídios empíricos para detectar algumas anomalias que, para usar uma idéia de Robert Dahl, desvirtuam a natureza democrática da democracia brasileira. Dentre essas, podemos destacar: 1) a excessiva personalização do voto e o baixo grau de partidarização das campanhas eleitorais, que dificulta o estabelecimento de vínculos de identidade mais sólidos entre eleitor e eleito (bem como com as legendas partidárias que os abrigam), sobre-representando nos órgãos legislativos brasileiros aqueles parlamentares de perfil mais fisiológico e clientelista e, portanto, mais dispostos a negociar "no varejo" seu apoio aos diferentes governos; 2) a lenta institucionalização das políticas de cotas e de inclusão de minorias, bem como a necessidade de institucionalizarem-se incentivos à participação política desses segmentos, somados à manutenção do sistema proporcional para aumentar a presença das mulheres e de outros grupos tradicionalmente sub-representados na cena política brasileira; 3) o alto custo das campanhas eleitorais que, por serem excessivamente caras e intransparentes, acabam estreitando os vínculos escusos dos políticos com os financiadores de campanhas, terminando por prejudicar a coerência das políticas governamentais, por meio da apresentação de emendas ao orçamento que visam a propiciar a transferência de recursos para as empresas financiadoras das campanhas dos candidatos; 4) o excesso de migrações partidárias, que se apresenta como um dos principais obstáculos à maior institucionalização do sistema partidário brasileiro (e, em conseqüência, da taxa alta de políticos de perfil mais fisiológico presentes nos órgãos legislativos); 5) permanência das taxas históricas de desigualdade regional no sistema político brasileiro, o que sobrerepresenta os partidos de centro-direita, especialmente no Senado Federal, conferindo-lhes um peso na arena legislativa desproporcional à sua relevância social, e 6) o presidencialismo brasileiro, ao contrário da democracia presidencialista pluripartidária do período democrático anterior, é mais "governável” e relativamente democrático, como o demonstram Limongi e Santos, embora apresente alguns "problemas" de funcionamento, seja se for julgado pelos critérios da otimização da coordenação da coalizão presidencial (Pereira e Mueller), seja se for julgado pelos parâmetros da institucionalização partidária e da constituição de governos de perfil programático 
mais definidos, cujos partidos possam ser responsabilizados com mais eficácia pelo eleitorado em virtude do fracasso ou do sucesso das políticas públicas implementadas pelos governos dos quais participam (Amorim Neto).

Em suma: o sistema político democrático brasileiro - assim como seu congênere norte-americano - é "governável” com as regras institucionais vigentes. Mas só a partir de parâmetros normativos excessivamente tacanhos podemos dar por encerrado aí o debate sobre o seu desempenho, inferindo de tal governabilidade que sejam inviáveis ou desnecessários aperfeiçoamentos institucionais incrementais (geralmente subsumidos na plataforma de uma "reforma política") para torná-lo mais democrático e mais inclusivo, ou seja, para aperfeiçoar e aprofundar a qualidade de nossa democracia, para usar as expressões caras a Robert Dahl. Acrescentemos ainda que é justamente a partir de tais critérios que se pode e deve-se rejeitar qualquer proposta de reforma política que, a pretexto de tornar a democracia brasileira mais “governável”, pretenda de fato torná-la menos democrática, reduzindo os níveis de competição política e de participação social dos cidadãos. Por outro lado, a partir da postura acima delimitada, não se pode também recusar in limine aquelas propostas que venham a agregar eficiência, representatividade e accountability ao sistema, sob o pretexto de que este já seja "governável”.

Concluindo, podemos afirmar que o importante livro organizado por Soares e Rennó consolida os esforços de reflexão de toda uma geração de pesquisadores sobre a evolução recente das instituições políticas democráticas brasileiras, colocando em novos patamares o debate sobre o desempenho de nosso sistema político. Desse ponto de vista, é a alta qualidade dos trabalhos reunidos e a prática de um estilo de análise política que busca sempre fundamentar com evidências e testes empíricos significativos as hipóteses e proposições teóricas formuladas - menos do que a suposta adesão a um modismo "neo-institucionalista" ou à platitude mais geral segundo o qual "as instituições contam" - que dá unidade aos vários textos incluídos na coletânea, fazendo que ela torne-se uma referência indispensável para a reflexão sobre as instituições políticas democráticas brasileiras, independente e autônoma dos influxos conjunturais da própria tramitação das propostas que constituem seu objeto de análise inicial.

Sérgio Soares Braga (ssbraga@ufpr.br) é Doutor em Ciências Sociais pela Universidade Estadual de Campinas (Unicamp) e professor de Ciência Política no Departamento de Ciências Sociais da Universidade Federal do Paraná(UFPR).

\section{REFERÊNCIASBIBLIOGRÁFICAS}

ALMEIDA, A. 2006. Amnésia eleitoral : em quem você votou para Deputado em 2002? E em 1998? In : SOARES, G. A. D. \& RENNÓ, L. (orgs.). Reforma política : lições da história recente. Rio de Janeiro : Fundação Getúlio Vargas.

AMORIM NETO, O. 2006. A reforma do sistema de governo : rumo ao parlamentarismo ou ao semipresidencialismo? In : SOARES, G. A. D. \& RENNÓ, L. (orgs.). Reforma política : lições da história recente. Rio de Janeiro : Fundação Getúlio Vargas.

AMORIM, M. C. \& CINTRA, A. 2003. Histórico de reformas. As reformas políticas e a Câmara dos Deputados. Brasília : Câmara dos Deputados. Disponível em : http://www2.camara.gov.br/internet/publicacoes/estnottec relatoriosespeciais/tema13/pdf/300413.pdf. Acesso em : 17.abr.2007.

ANASTASIA, F. \& AVTRIZER, L. 2006. Reforma política no Brasil. Belo Horizonte : UFMG.

ARAÚJO, C. 2006. Condicionantes institucionais das políticas de cotas. In : SOARES, G. A. D. \& RENNÓ, L. (orgs.). Reforma política : lições da história recente. Rio de Janeiro : Fundação Getúlio Vargas.

BENEVIDES, M. V.; VANUCHI, P. \& KERCHE, F. (orgs.). 2003. Reforma política e cidadania. São Paulo : Fundação Perseu Abramo.

BOHN, S. 2006. Ainda o velho problema da distorção da representação dos estados na Câmara dos Deputados In : SOARES, G. A. D. \& RENNÓ, L. (orgs.). Reforma política : lições da história recente. Rio de Janeiro : Fundação Getúlio Vargas. 
BRAGA, M. S. 2006. Dinâmica de coordenação eleitoral em regime presidencialista e federativo : determinantes e conseqüências das coligações partidárias no Brasil. In : SOARES, G. A. D. \& RENNÓ, L. (orgs.). Reforma política : lições da história recente. Rio de Janeiro : Fundação Getúlio Vargas.

BRAGA, S. \& BELACHE, P. 2004. O estudante de pós-graduação em Sociologia Política da UFPR e a questão da reforma política. Paraná Eleitoral, Curitiba, v. 53-54, p. 13-37, jul.-dez .

DAHL, R. 2003. ¿Es democrática la constitución de los Estados Unidos? Buenos Aires : Fondo de Cultura Económica.

DIRCEU, J. \& IANONI, M. 1999. Reforma política. Instituições e democracia no Brasil atual. São Paulo : Fundação Perseu Abramo.

FIGUEIREDO, A. \& LIMONGI, F. 1999. Executivo e Legislativo na nova ordem constitucional. Rio de Janeiro : Fundação Getúlio Vargas.

2006. Poder de agenda na democracia brasileira : desempenho do governo no presidencialismo pluripartidário. In : SOARES, G. A. D. \& RENNÓ, L. (orgs.). Reforma política : lições da história recente. Rio de Janeiro : Fundação Getúlio Vargas.

JAGUARIBE, H. 1999. Sistema político e governabilidade democrática. Brasília : Instituto Teotônio Vilela.

LIJPHART, A. 2003. Modelos de democracia. Desempenho e padrões de governo em 36 países. Rio de Janeiro :Civilização Brasileira.

LIMONGI, F. 2005. Reforma política no Brasil. Estudos e pesquisas n. 120. Rio de Janeiro : Instituto Nacional de Altos Estudos. Disponível em : http://www.inae.org.br/publi/ep/EP0120.pdf. Acesso em : 17.abr.2007.

2006. Presidencialismo, coalizão partidária e processo decisório. Novos Estudos Cebrap, São Paulo, v. 76, p. 17-41, nov. Disponível em : http://www.scielo.br/pdf/nec/n76/02.pdf. Acesso em : 17.abr.2007.

MACHADO, S. 1998. Relatório final da Comissão Temporária Interna encarregada de estudar a reforma político-partidária. Brasília : Senado Federal. Disponível em : http://www.senado.gov.br/web/relatorios/ CEsp/RefPol/relat.htm. Acesso em : 17.abr.2007.

MATEO-DIAZ, M. 2006. Em busca da panacéia para igualdade duradoura : sobre a arte de combinar soluções rápidas e medidas estruturas para aumentar a presença de mulheres no Parlamento. In : SOARES, G. A. D. \& RENNÓ, L. (orgs.). Reforma política : lições da história recente. Rio de Janeiro : Fundação Getúlio Vargas.

MELO, C. R. 2006. Sistema partidário, presidencialismo e reforma política no Brasil. In : SOARES, G. A. D. \& RENNÓ, L. (orgs.). Reforma política : lições da história recente. Rio de Janeiro : Fundação Getúlio Vargas.

MORAES, F. \& HERMANNS, K. 2003. Reforma política no Brasil. Realizações e perspectivas. Fortaleza : Fundação Konrad Adenauer.

NICOLAU, J. 2006a. Voto personalizado e reforma eleitoral no Brasil. In : SOARES, G. A. D. \& RENNÓ, L. (orgs.). Reforma política : lições da história recente. Rio de Janeiro : Fundação Getúlio Vargas.

2006b. Dando força aos partidos brasileiros. Insight Inteligência, Rio de Janeiro, p. 42-50, out.-dez. Disponível em : http://200.196.50.110/insight/inteligencia/num35/pdf/mat02.pdf. Acesso em : 17.abr.2007.

NORRIS, P. (ed.). 1999. Critical Citizens : Global Support for Democratic Governance. Oxford : Oxford University.

PEREIRA, C. \& MUELLER, B. 2006. Regras eleitorais e poderes do presidente no Congresso : duas dimensões complementares da capacidade governativa. In : SOARES, G. A. D. \& RENNÓ, L. (orgs.). Reforma políti$c a$ : lições da história recente. Rio de Janeiro : Fundação Getúlio Vargas.

RABAT, M. N. 2003. Histórico de reformas. A que se refere a expressão "reforma política” nas discussões em curso no Congresso Nacional. Brasília : Câmara dos Deputados. Disponível em : http://www2.camara.gov.br/ publicacoes/estnottec/relatoriosespeciais/tema13/pdf/207705.pdf. Acesso em : 17.abr.2007.

RENNÓ, L. 2006. O dilema do rico : número de candidatos, identificação partidária e accountability nas eleições de 2002 para a Câmara dos Deputados. In : SOARES, G. A. D. \& RENNÓ, L. (orgs.). Reforma política : lições da história recente. Rio de Janeiro : Fundação Getúlio Vargas. 
SAMUELS, D. 2006. Financiamento de campanhas no Brasil e propostas de reforma. In : SOARES, G. A. D. \& RENNÓ, L. (orgs.). Reforma política : lições da história recente. Rio de Janeiro : Fundação Getúlio Vargas.

SANTOS, A. M. 2006. Regras eleitorais, deputados e fidelidade partidária. In : SOARES, G. A. D. \& RENNÓ, L. (orgs.). Reforma política : lições da história recente. Rio de Janeiro : Fundação Getúlio Vargas.

SANTOS, F. 2003. O poder Legislativo no presidencialismo de coalizão. Belo Horizonte : UFMG.

2006. Em defesa do presidencialismo de coalizão. In : SOARES, G. A. D. \& RENNÓ, L. (orgs.). Reforma política : lições da história recente. Rio de Janeiro : Fundação Getúlio Vargas.

SERRA, J. 1995. Reforma política no Brasil. São Paulo : Siciliano.

SOARES, G. A. 2001. A democracia interrompida. Rio de Janeiro : Fundação Getúlio Vargas.

SOARES, G. A. D. \& RENNÓ, L. 2006. Introdução : projetos de reforma política na Câmara dos Deputados. In : (orgs.). Reforma política : lições da história recente. Rio de Janeiro : Fundação Getúlio Vargas.

TAVARES, J. A. G. 1998. Reforma política e retrocesso democrático. Agenda para reformas pontuais no sistema eleitoral e partidário brasileiro. Porto Alegre : Mercador Aberto. 